\title{
If Ever the Twain Shall Meet: Graph Theoretical Dimensions of Formal and Informal Organization Structure
}

\author{
Starling Hunter ${ }^{1}$ \\ ${ }^{1}$ College of Business Administration, Carnegie Mellon University Qatar, Doha, Qatar \\ Correspondence: Starling D. Hunter, 5032 Forbes Ave., Qatar Office SMC 1070, Pittsburgh, PA, USA.
}

Received: August 29, 2016

Accepted: September 8, 2016

Available online: September 10, 2016

doi:10.11114/ijsss.v4i10.1872

URL: http://dx.doi.org/10.11114/ijsss.v4i10.1872

\begin{abstract}
Formal and informal organization structure have been described as "opposing poles of a duality" - one which has yet to be fully resolved. The aim of this paper is to detail an approach to treating both structures in a comparable way, an approach that explicitly recognizes core and underlying commonalties. Two distinct analytical strategies are employed to this end. The first involves a detailed comparison and contrast of selected and relevant structural dimensions drawn from the two research streams. The second strategy involves the application of these dimensions to the study of network graphs of both the formal and informal structures of the same organization at the same point in time.
\end{abstract}

Keywords: organization structure, organization design, network analysis, social network analysis, organizational network analysis, hierarchy, decentralization, centralization, division of labor, span of control

\section{Introduction}

Formal and informal organization structure have been described as "opposing poles of a duality" - one that has yet to be fully resolved (Gulati \& Puranam, 2009). Perhaps nowhere is this more evident than in the conceptual vocabularies used to describe them. In the case of the latter, particularly in the field of organizational sociology, the current lexicon is replete with concepts adopted from social network analysis and graph theory, terms like term centrality, geodesic distance, equivalence, ego network, betweenness, density, and reachability to name but a few. In the case of formal organization structure, particularly in management and administrative theory, we find many terms in use that were initially developed by the pioneers of organizational studies, terms such as centralization, span-of-control, scalar chain, vertical and horizontal differentiation, specialization, formalization, and configuration.

Another manifestation of this duality is the difference in the relationships that underlie these contrasting aspects of structure. Formal structure is based upon the reporting or authority relationship (Blau, 1968) while informal structure can be based upon any of a large number of other social relations, such as advice-seeking, communication, trust, knowledge sharing, and friendship (Kilduff \& Krackhardt, 2008). Further, the reporting relationship links only superiors and their subordinates while the informal ties can, at least theoretically, exist between any two members of an organization, as well as the superior and subordinate. Also adding to the sense of duality is the almost complete bifurcation within the research literature linking structure to organizational performance (Diefenbach \& Sillince, 2011). Most such studies focus on one form of structure or the other (Tichy \& Fombrun, 1979; Hunter 2015). Very few even acknowledge the existence of the other form of structure, let alone directly test propositions concerning the effect of one upon the other or their joint effect on performance. The aim of this paper is to detail an approach to treating both structures in a comparable way, an approach that explicitly recognizes core and underlying commonalties. Two distinct analytical strategies are employed to this end. The first involves a detailed comparison and contrast of selected and relevant structural dimensions drawn from the two research streams. The second strategy involves the application of these dimensions to the study of network graphs of both the formal and informal structures of the same organization at the same point in time.

The remainder of this paper is organized as follows. The next section summarizes some recent approaches to conceptualizing formal and informal structure in similar terms, with particular emphasis given to Hunter's (2015) comparative analysis of a dozen formal and informal measures of structure, as well as Krackhardt's (1994) graph theoretical dimensions of informal organization. The ensuing section contains a discussion of three specific limitations to the application of the latter set of dimensions to the study of formal structure. In the fourth section a relatively small 
set of graph theoretical and graph-like measures are applied to the analysis of the formal and informal structures of the same firm as detailed by Krackhardt \& Hanson (1993). The paper ends with a discussion of the implications of defining both aspects of structure with same set of graph theoretical and graph-like terms and how doing so might inform future research on the structure-performance relationship.

\section{Some Graph Theoretical Dimensions of Formal \& Informal Organization Structure}

As suggested in the introduction, formal and informal structures represent poles of a duality whose resolution is perhaps hampered by the lack of a common conceptual vocabulary. As noted by Hunter (2015), the idea that formal and informal structure could and should be studied together and with similar terminology is not new. In fact, this point was made emphatically, almost four full decades ago, by Tichy \& Fombrun (1979, p. 926) in their discussion about "prescribed" and "emergent" structures:

We make a clear distinction between prescribed and emergent networks because...within an organization, there exists a multiplicity of social structures that arise out of the many possible types of social relationships that tie people to one another. Only a portion of the social structure is prescribed...Thus, unplanned structures and behavior patterns will always emerge. These emergent structures and behavior patterns have been misleadingly labeled the "informal organization" and are never treated empirically and conceptually together with formal structure. We argue that they should be treated together...each...has its own social and functional logic. Each is amenable to similar systematic analysis. (emphasis added).

The apt title of that paper was Network Analysis in Organizational Settings and as it suggests, the authors argued that the application of social network analysis to the study of formal structure was their preferred approach to resolving the duality. Despite the compelling and clarion nature of the call that went forth, it has gone largely unheeded, perhaps most conspicuously so in the study of structure and performance above the group/team level. At the unit/departmental and organizational levels, management and administrative theorists have continued their focus on structural contingency theory (Donaldson, 1987, 2001) and its variants such as the information processing theory of organization design (Burton \& Obel, 1998) and configuration theory (Doty, Glick, \& Huber, 1993; Miles, Snow, Meyer, \& Coleman 1978). A secondary stream in the management and public administration literatures has focused on non-contingent relationships between formal structure and performance. In both cases the emphasis has been almost exclusively on vertical and horizontal measures of structure such as span of control (Bohte \& Meier, 2000; Theobald \& Nicholson-Crotty, 2005) and vertical span, i.e. the number of levels in the hierarchy (Maguire, 2009; Armandi \& Mills, 1985; Carillo \& Kopelman, 1991). At the same levels of analysis, organizational sociology has continued to focus on informal or emergent relationships such as inter-personal communications (Cummings \& Cross, 2003; Crowston \& Howison, 2006), hindrance (Sparrowe, Liden, Wayne, \& Kraimer, 2001), advice-seeking (Sarkar, Feinberg, \& Krackhardt, 2010), friendship (Mehra, Dixon, Brass, \& Robertson, 2006) and knowledge-sharing (Reagans, Zuckerman, \& McEvily, 2004).

While there is little if any empirical research that incorporates both formal and informal measures of structure, three studies have established a foundation for doing so-Krackhardt (1994), Everett \& Krackhardt (2012), and Hunter (2015). In the former the author identified four, independent, graph theoretical measures that "establish a pure structure as a standard against which other structures can be compared" and which thereby specify the degree to which any informal organization or other social system is hierarchically structured. The second study was an extension and clarification of the conditions under which those four conditions were operative. The latter study compared and contrasted of over a dozen formal and informal measures of structure - Krackhardt's among them — ultimately placing them into four broad categories - measures of centrality, cohesion, equivalence, and hierarchy. One matter not discussed was Krackhardt's representation of formal organization structure as an out-tree rather than as an in-tree or even as an undirected one. While seemingly a minor consideration, this distinction is highly important when attempting to understand - in graph theoretical terms - the relationship between the formal and informal structures of an organization. As such, the next section includes an in-depth discussion of the matter of direction and demonstrates that from it follows at least three limiting conditions to the application of Krackhardt's four measures to formal organization structure.

\section{Krackhardt's Graph Theoretical Dimensions (GTD) of Informal Structure}

As suggested above, Krackhardt (1994) identified four, independent, graph theoretical measures that "establish a pure structure as a standard against which other structures can be compared" and which thereby specify the degree to which any informal organization or other social system is hierarchically structured. Those measures - which are described in greater detail below - are connectedness, efficiency, graph hierarchy or reciprocity, and least upper boundedness. In that study, social structures are said to be hierarchical in direct proportion to their divergence from maximal values of those four measures. The "out-tree" served as the archetype of a pure hierarchy. As can be seen in Figure 1, out-trees are 
directed graphs (digraphs) whose every point, except for the root (node A), has one arrow directed towards it but may have several emanating therefrom.

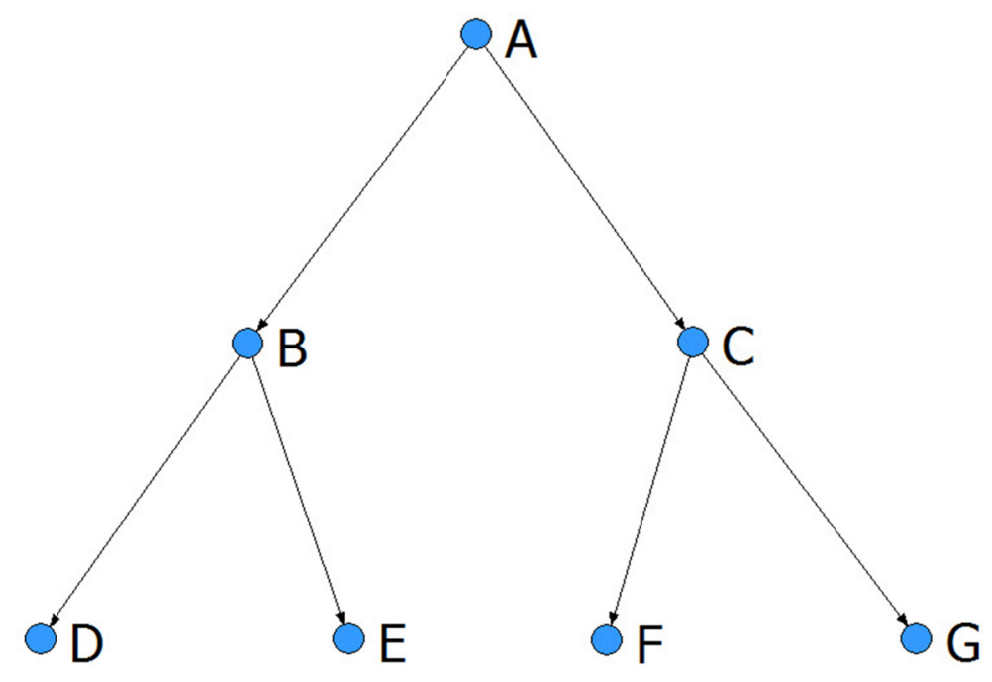

Figure 1. An Out-Tree

Recall that the first of the Krackhardt's four dimensions is connectedness. In short, a digraph is connected if it contains no isolates, i.e. all nodes belong to the same one component. A violation of the connectedness condition occurs when any point in the graph is unable to reach any other point. The second of the four measures is graph hierarchy, a condition requiring that for every pair of nodes, one can reach the second, but the second can't reach the first. Violations of this condition occur when the ties between all pairs of nodes are not strictly ordered in this manner. The third condition is graph efficiency. In short, an out-tree of $\mathrm{n}$ nodes is efficiently connected by $\mathrm{n}-1$ lines or edges. Fewer than this number breaks the graph into two or more components while more edges than this indicates that more than the minimum number are present. Every additional line or edge beyond n-1 constitutes a violation of the graph efficiency condition. The final measure is what Krackhardt termed least upper boundedness. He stated that a pair of actors has an upper bound when there is a third actor to whom they both "defer" or have access. Since a given pair of actors may have many upper bounds in a network, the "least" upper bound is the "member of the set of upper bounds who, in turn, can appeal to or defer to the remaining upper bounds" (ibid., p. 99).

\subsection{Applying the GTD to Formal Organization Structure}

Taken together the four GTD define an out-tree, a structure which in turn serves as a standard against which the informal structure of an organization (or other social system) can be precisely measured. Because the graph theoretical properties of out-trees share much in common with formal organization structure and its graphical depiction as an organization chart, it's not surprising that several specific comparisons are made throughout Krackhardt's discussion. Chief among them is the notion that the out-tree structure preserves "several fundamental principles of classic organizational structure including the unity of command, unambiguous chain of command, and the scalar principle" (ibid., p. 94) More specifically, in the discussion of graph hierarchy, we are told that the non-reciprocity required of this condition is reflected in the authority relationship that underlies formal organization structure. In particular, superiors can command not only their own subordinates but can "reach" through to the chain of command to their subordinates' subordinates. However, subordinates cannot reach the superior in the same way. That is to say, one can't be the superior of his superior, or of any other higher ranking employee. And in the discussion of least upper boundedness, we are told that "in a formal organization chart, the LUB of two employees is that closest boss who has formal authority over both of them" (ibid., p.99). We're also told that the LUB condition preserves the unity-of-command principle, i.e. it ensures that there is only one "chief executive" at the top (ibid., p. 100)

\subsection{Invariance of the GTD across Formal Structure}

While the GTD are useful in describing how informal structures diverge from the standard they define, there are issues attendant to their application to the study of formal organization structure. The first and most obvious is that if the four GTD can be used to define a pure hierarchy, and if formal organization structure is an archetypal example of such, then the GTD are necessarily invariant across any set or sample of formal organization structures. Specifically, all four GTD must assume the value of unity (1.0) for any and all formal organization structures. 
Another important point regarding the application of the GTD to formal structure is that they are also invariant across certain sub-graphs of an out-tree. Specifically, the four GTD have the value of unity for the entire seven-node out-tree shown in Figure 1, above, as well as for every connected sub-graph of three or more nodes. Specifically, the four GTD all assume the value of unity for the four line graphs- $\{\mathrm{ABD}\},\{\mathrm{ABE}\},\{\mathrm{ACF}\}$, and $\{\mathrm{ACG}\}$ - as well for those with two or more branches, e.g., $\{A B C\},\{A B C D\},\{A B C D E\}$ and $\{A B C D E F\}$. In the parlance of formal organization theory, the four line graphs are organization's scalar chains or chains of command linking the root to the bottom of the tree. The many larger sub-graphs would be said to be comprised of a set of several scalar chains with a common root. Unlike the line graphs, these larger sub-graphs exhibit both vertical and horizontal differentiation, the latter being evidenced by the existence or one or more nodes with one or more branches. The GTD do not, however, capture this distinction among the sub-graphs. Nor do they distinguish between the extent of vertical differentiation, i.e. the length of the scalar chains. This is all notable because the vertical and horizontal dimensions are the basic building blocks of formal organization structure, at least as depicted in organization charts. It is along the vertical axis that the hierarchy of formal authority manifests itself (Blau, 1968) and it is along horizontal one that the division of labor, departmentalization, and specialization so manifest (Blau, 1970).

\subsection{Is Formal Structure an Out-tree?}

A third set of difficulties arises from the fact an out-tree may be but a partial representation of formal organizational structure. As noted above, administrative and management theorists are given to conceptualizing formal structure in terms of the reporting relationship linking superiors and their subordinates. But few, if any, conceptualize it solely in these terms, i.e. as only a vehicle for the exercise of authority or status. Rather, concomitant to the chain of command is a two-way channel of communication (Bolton \& Dewatripont, 1994; Harris, 2002; Oberg \& Walgenbach, 2008). The superior's authority to command implies that subordinates are required to report on their activities. To consent to be supervised means to agree to report or to provide information on progress towards the accomplishment of ends, as well as the means taken to those ends. As such, communication flows back, opposite of the direction of the arrow of authority (Reitzig \& Maciejovsky, 2014). That there are "costs" associated with the provision of that information is also generally understood (Daft, 2012; Everett \& Krackhardt, 2012). In graph theoretical terms, the authority relationship is not and can be reciprocated: authority flows downward, but communication flows in both directions along the formal hierarchy — orders down and reports up.

This all suggests that there is some justification for conceptualizing formal organization structure as a multiplex network comprised - at a minimum - of both authority and communication relations. Graphically, this composite network could be represented a non-directed graph as is the custom with organization charts. In terms of the four GTD, this conceptualization of formal organization structure makes it a strongly connected tree that is also graph efficient and whose least upper bound is always the closest common supervisor while the "most" upper bound is the root. One implication of this conceptualization is that hierarchy is inferred by the shape of network rather than the direction of the ties among pairs of nodes. The important shape requirements are the existence of two or more line graphs that (1) have path lengths greater than or equal to two (2) originate in the same root (3) terminate in different nodes and that (4) have at least one intermediate node with more than one branch. The minimal number of nodes required to meet these four conditions would be seven, essentially an undirected version of the graph shown in Figure 1.

One interesting implication of viewing formal organization as such a multiplex network is that only a few basic concepts from classical administrative and the graph-theory are required to develop a typology of any and all dyads in a formal organization. From the former we need only the terms scalar chain, and hierarchy of authority, i.e. superior and subordinate, as well as vertical differentiation or hierarchical level. And from the graph-theoretical approach we need only the concepts of neighborhood and equivalence. As shown in Table 1, the eight categories thereby derived evidence a clear symmetry: in relation to egos, all alters are one of eight kinds defined by combinations of authority and/or equivalence relations. 
Table 1. A Classification of Dyads

\begin{tabular}{|c|c|c|c|}
\hline \multicolumn{3}{|c|}{ If the tie emanating from the ego passes... } & \multirow{2}{*}{$\begin{array}{l}\text { then the alter is... } \\
\text { a superior of ego's superior. }\end{array}$} \\
\hline \multirow{2}{*}{$\begin{array}{l}\text { along its scalar } \\
\text { chain, }\end{array}$} & $\begin{array}{l}\text { and reaches } \\
\text { upwards, }\end{array}$ & $\begin{array}{l}\text { and passes out of ego's } \\
\text { neighborhood, } \\
\text { and stays within ego's } \\
\text { neighborhood, }\end{array}$ & \\
\hline & $\begin{array}{l}\text { and reaches } \\
\text { downwards, }\end{array}$ & $\begin{array}{l}\text { and stays within ego's } \\
\text { neighborhood, } \\
\text { and passes out of ego's } \\
\text { neighborhood, }\end{array}$ & a subordinate of ego's subordinate. \\
\hline \multirow{2}{*}{$\begin{array}{l}\text { off its scalar } \\
\text { chain, }\end{array}$} & $\begin{array}{l}\text { and stays on the } \\
\text { same hierarchical } \\
\text { level, }\end{array}$ & $\begin{array}{l}\text { and stays within the } \\
\text { neighborhood of ego's superior, } \\
\text { and passes out of the } \\
\text { neighborhood of ego's superior, }\end{array}$ & $\begin{array}{l}\text { ego's (structural or regular) } \\
\text { equivalent }{ }^{1} \\
\text { ego's regular equivalent. }^{2}\end{array}$ \\
\hline & $\begin{array}{l}\text { and reaches a } \\
\text { different } \\
\text { hierarchical level, }\end{array}$ & and reaches downwards, & $\begin{array}{l}\text { a regular equivalent of (one of) ego's } \\
\text { superior(s). }\end{array}$ \\
\hline
\end{tabular}

The first four classes are distinguished by three underlying dimensions: (1) whether or not the tie extending from ego lies along the scalar chain or not (2) whether or not the tie is directed "up" the scalar chain, i.e. toward the root or not and (3) whether the tie extends beyond ego's neighborhood or not. The second four classes are defined by similar but not precisely analogous dimensions: (1) whether or not the tie extending from ego lies along the scalar chain (2) whether or not the alter is on the same hierarchical level (3) whether or not the tie extends beyond the neighborhood of ego's superior and (4) whether or not the tie is directed upwards.

Clearly, the typology need not be restricted to only communication or communication-intensive relations. Rather, it may be applied to the analysis of any informal relationship that ties together individuals in an organization alongside the formal structure. In order to demonstrate the typology's potential contribution to resolving the formal/informal structure duality, it is applied in the next section to Krackhardt \& Hanson's (1993) Leers Computer case. That case is particular useful for this study's stated purposes because it includes information about two informal structures in that organization - trust and advice-seeking — as well as the formal organization structure.

\section{Case Study: Leers Computer}

Krackhardt \& Hanson 's (1993) Leers Computer case, which originally appeared in the Harvard Business Review, describes not only the formal organization structure of the firm, as shown in Figure 2, but also detailed two informal structures - the advice seeking and the trust networks, as shown in Figures 3 and 4, respectively. In an overview of the company's situation we are told that the CEO of this California-based, 28-member firm had, over a 15-year period, "trained a cadre of loyal professionals who had built a strong regional reputation for delivering customized office information systems." The firm was divided into four major departments-Field Design, Software Applications, Integrated Communication Systems, and Data Control Systems. The former generated the largest proportion of the firm's revenues and had been the "linchpin of the operation, led by the company's technical superstars," workers with whom Leers "kept in close contact." To address competitive challenges in the marketplace, Leers established a cross-departmental task force headed by an eight-year veteran named Tom Harris. Under his leadership the task force quickly became "deadlocked by members championing their own agendas." In order to help identify the nexus of the problem, Leers commissioned an analysis of the company's advice and trust networks. The subsequent analysis revealed that Harris was very centrally positioned in the advice-seeking network but very peripheral in the one formed by trust relations. 


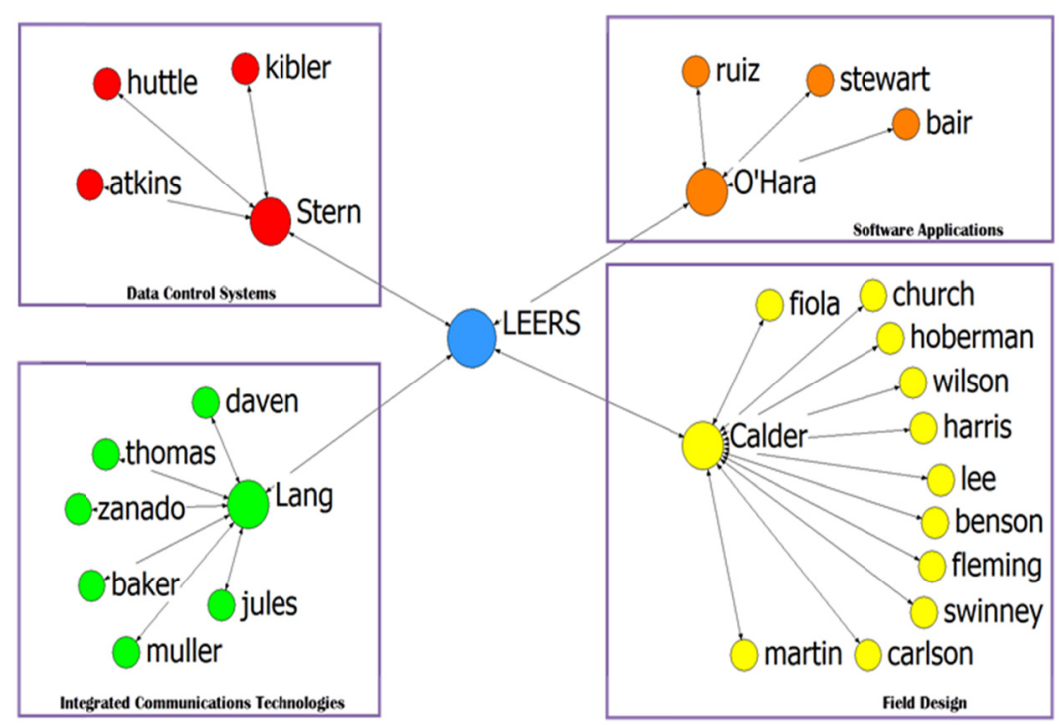

Figure 2. Formal \& Informal Structures at Leers Computer: Formal Structure as an Undirected Network

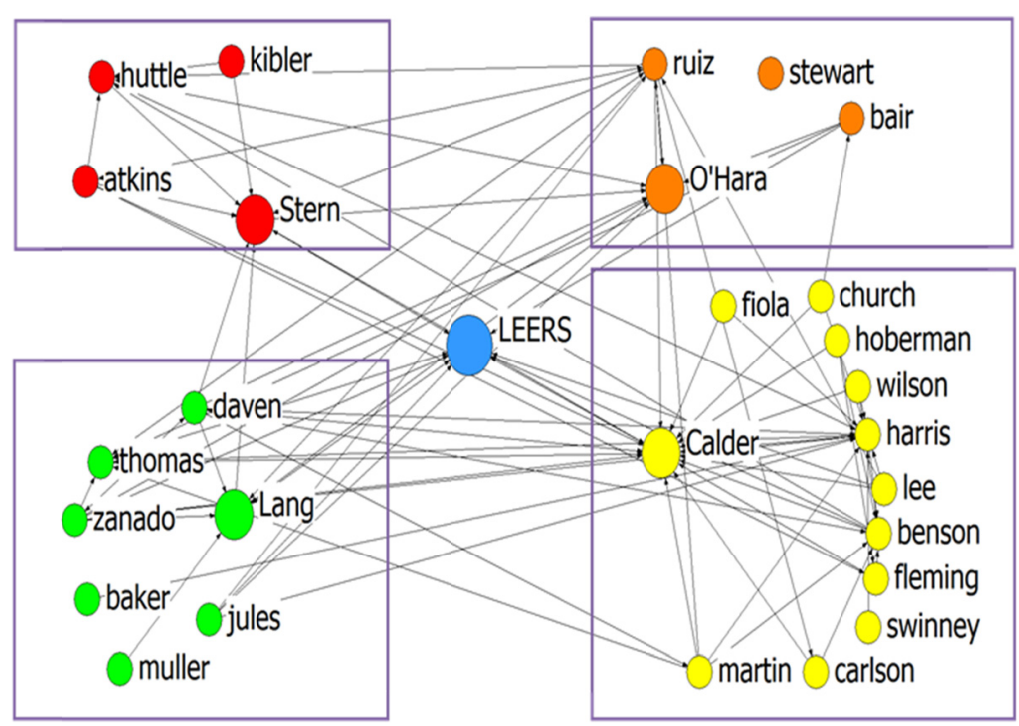

Figure 3. Formal \& Informal Structures at Leers Computer: Advice Network Overlaid on Departmental Boundaries 


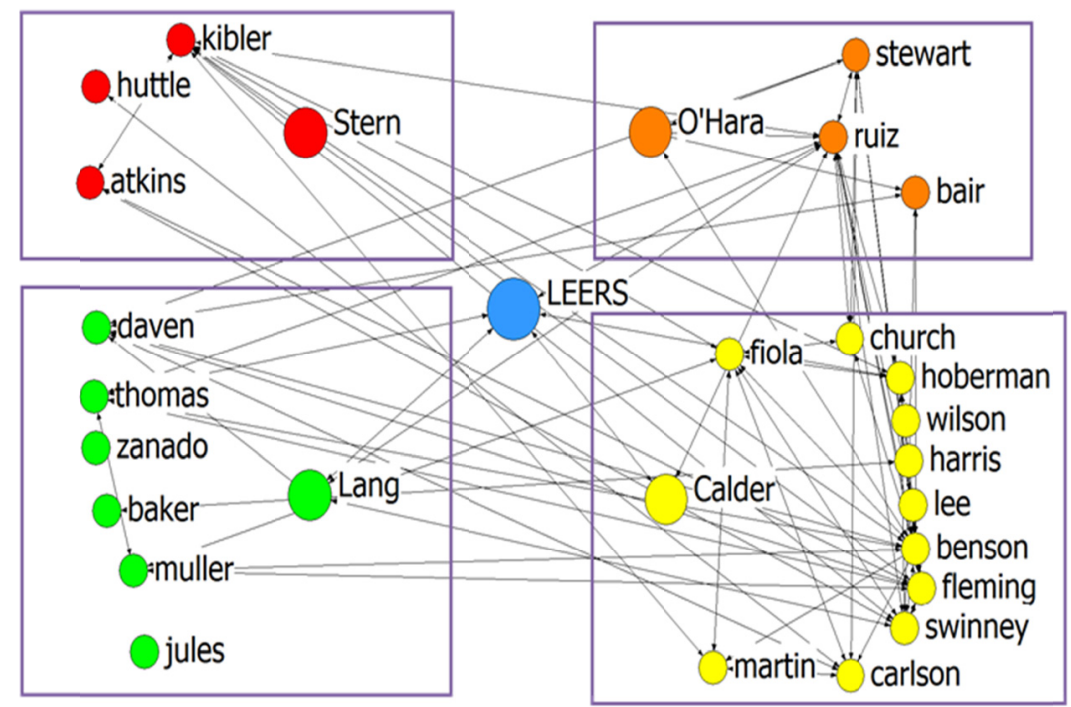

Figure 4. Formal \& Informal Structures at Leers Computer

Trust Network Overlaid on Departmental Boundaries

Table 2 contains values of several graph theoretical and graph-like structural dimensions of the formal and the two informal structures. With regard to the formal structure, three of the GTD are equal to unity-connectedness, graph efficiency, and LUBedness. Because all connections are undirected then, as expected, the hierarchy score is equal to zero - the lowest possible value. The diameter of the network is 4 because the longest of the shortest paths connecting all pairs of nodes occurs between pairs at the bottom of the hierarchy, i.e. between two non-supervisory employees. The mean geodesic distance is 3.05 while the span of control for the five supervisory employees (Leers, O'Hara, Calder, Stern, and Lang) is equal to 5.40, which is also the average of the degree centrality of the Leers (4) plus one less than the degree centralities of the other four managers.

Table 2. Dimensions of Formal \& Informal Structures at Leers Computer

\begin{tabular}{lclcccc}
\hline & & Reporting & Advice & $\begin{array}{c}\text { Reporting }+ \\
\text { Advice }\end{array}$ & Trust & $\begin{array}{c}\text { Reporting } \\
+ \text { Trust }\end{array}$ \\
\hline Krackhardt's & Connectedness & 1.000 & 0.929 & 1.000 & 0.614 & 1.000 \\
Graph & Efficiency & 1.000 & 0.834 & 0.832 & 0.786 & 0.826 \\
Theoretical & Hierarchy & 0.000 & 0.596 & 0.000 & 0.000 & 0.000 \\
& LUB & 1.000 & 0.834 & 1.000 & 1.000 & 1.000 \\
Other Graph & Reachability & $100 \%$ & $55.2 \%$ & $100 \%$ & $61.4 \%$ & $100 \%$ \\
Theoretical & Ties & 27 & 92 & 122 & 67 & 176 \\
Dimensions & Geodesic Dist. & 3.05 & 2.57 & 2.29 & 1.86 & 2.04 \\
& Diameter & 4 & 7 & 4 & 4 & 4 \\
Classical & Span of Control & 5.40 & & & & \\
Measures & Vertical Differentiation & 3.00 & & & & \\
& Horizontal Differentiation & 3.00 & & & & \\
& Subordinate/Supervisor Ratio & 4.60 & & & & \\
\hline
\end{tabular}

\subsection{The Advice Network}

The values of these dimensions in the advice network are a stark contrast. As expected, none of the four GTD are valued at unity. Connectedness is less than unity because one employee (Stewart) did not appear in the advice network, the assumption being that he neither sought out others for advice nor was sought out by them. Because several pairs of 
employees sought out one another for advice, the graph hierarchy score had to be less than unity. Because there were far more connections than the minimum necessary, the graph efficiency score was also well less than unity. Finally, because all pairs of employees did not have a least upper bound, the LUB score was also less than unity.

As for the other dimensions, the advice network has 92 links, an increase of $70 \%$ over the formal structure. The mean geodesic distance is only 2.57 which is $16 \%$ lower than that for the formal structure. On the other hand, the diameter is 7 which is $75 \%$ larger. The reachability of nodes is only $55.2 \%$ versus $100 \%$ in the formal structure. This is due to two things. First, there is one isolate in the advice network versus whereas there are none in the formal structure. Second, eleven of the 28 nodes had in-degree centralities of 0 which effectively means that the flow of advice seeking does not reach them directly. Rather, they are only reached by way of their supervisors. Finally, while the supervisory employees comprise only $18 \%$ of the workforce ( 5 of 28 ), they are implicated in $1 / 3^{\text {rd }}$ of the advice ties. Thus, supervisors are over-represented in the advice network, just as previous research has shown (Lazega \& van Duijn, 1997).

\subsection{Combined Formal Structure \& Advice Network}

When the advice network and formal structure are viewed as a multiplex network, an interesting pattern of emerges among the dimensions of structure. First of all, we now find that only two of the four GTD have a value of unity - LUBedness and connectedness. Hierarchy is still zero and graph efficiency, at a value of 0.832 , is only slightly lower than its value of 0.834 in the advice network alone. The number of ties in the combined network is 122 which is 24 fewer than the sum of the two networks taken independently. This indicates that there are 24 connections that are redundant between the two networks. As we see in Table 3, below, twenty-one of those are directed from subordinate to superior while only three are in the opposite direction. Accordingly, the QAP correlation between the formal and advice network, which equals 0.274 , is highly significant $(p<0.0001)$. The mean geodesic distance of the combined network is only 2.29 which represents an $11 \%$ drop from the advice network alone and an almost $25 \%$ decrease from that of the formal structure. Because the formal structure has full reachability, so too does the combined network. Also, the diameter decreases from a value of 7 in the advice network back to a value of 4 in the combined network, the same value that it had in the formal structure. Thus, in the combined network the number of links is greater and the average geodesic distance is lower than either of the networks that comprise it. Further, the reachability is higher and the diameter is shorter than that in the advice network alone.

\subsection{The Trust Network}

The pattern of values of the structure dimensions within the trust network exhibit some important similarities with and differences from those associated with the advice-seeking relation. Three of the four GTDs diverge from unity, LUBedness being the only exception. Hierarchy is zero because no links were directed. Connectedness equals 0.614 , an amount $34 \%$ lower than in the advice network. Efficiency is 0.786 , which is nearly $7 \%$ lower. The network has 67 pairs of nodes whose connections are not directed, and several components. Specifically, the main component has 22 nodes, the second component has only one pair of nodes while the remaining four components are comprised of single nodes, i.e. isolates. Thus, the reachability in the trust network is quite low at $61.4 \%$ which is slightly greater than what was observed in the advice network. The geodesic distance of the trust network is only 1.862 which is $39 \%$ lower than that in the formal structure and its diameter is only four. The five supervisory employees - who comprise $18 \%$ of the total workforce - were a party to only 10 pairs of trust ties or $15 \%$ of the total. Among those, only six of them- $9 \%$ of the total-were between supervisor and subordinate. Thus, whereas supervisor-subordinate ties were strongly over-represented in the advice network, they were quite under-represented in the trust network.

\subsection{Combined Formal Structure \& Trust Network}

In the combined network of trust and formal structure relations, two of the GTDs still have values of unity - connectedness and LUBedness. Because all ties are undirected, hierarchy equals zero. The network has 176 ties which is well over the minimum. Thus efficiency is less than unity (0.826). Because over $90 \%$ of the trust ties do not involve ties between supervisor to subordinate, it is not surprising that QAP correlation between the two networks is only 0.033 which is not statistically significant. The mean geodesic distance of this combined network is 2.037 , which is slightly higher than in the trust network alone but still $1 / 3^{\text {rd }}$ lower than that of the formal structure. Its diameter is four, the same as the formal structure. Finally, the reachability of this combined network is $100 \%$.

4.5 Distribution of Dyads

As shown in Table 3 all pairs of ties in the formal and the two informal structures may be placed into eight categories which are themselves based upon the nodes' position in the formal structure and/or role in the informal structure. The first category or grouping recognizes that the individuals who can be structural equivalents in the organization's former structure are those at the bottom (lowest level) of the organization hierarchy and who report to the same boss. In the advice and trust networks there are several connections among workers that are structural equivalents in the formal organization structure. Specifically, in the advice network 18 pairs of nodes (19.6\%) linked two of the formal structural equivalents while 20 pairs $(29.9 \%)$ did so in the trust network. 
The second category is based on the fact that regular equivalents in the formal organization structure would be employees at the same level — whether in the same department or not—but who report to a different superior. Again, while the formal structure will not evidence any such ties, the advice seeking and trust relationships can and do. Specifically, the former had 29 such ties (31.5\%) while the latter had 34 (50.7\%). Notably, in both networks this category of ties was the largest of the eight.

The next six categories are all formed by different kinds of "non-equivalents" in the formal structure, i.e. dyads that are neither structural nor regular equivalents. The first two of these have ties directed from superior to superordinate and vice versa. In the formal structure, all 27 of the ties belong to the former. In the advice network there was a great deal of overlap with the reporting/authority relationship. Specifically, of the 24 dyads (26\%) of these two types in the advice network, 21 of them $(87.5 \%)$ were directed from subordinate to superior. In the trust network, the picture was very different. Here there were many fewer such dyads - only $6(9.0 \%)$. But because information was not provided on the direction of the ties, it is not possible to provide a more detailed breakdown. Still, the percentage of superior-subordinate dyads in this trust network is only about $1 / 3^{\text {rd }}$ of that in the advice network.

The next two non-equivalent categories are comprised of dyads comprising individuals on the same scalar chain or chain of command, either above the boss or below the subordinate. In contemporary management parlance these are often termed "skip-level" contacts. While there are no such dyads in the formal structure, there are in the informal networks - but very few. In the advice network there were only $7(7.6 \%)$ and six of those were directed upwards in the scalar chain. In the trust network there were only 3 such dyads (4.4\%). The totals for these dyads were the smallest of any in the two networks.

The final two non-equivalent categories are comprised of dyads that cross both a hierarchical and a departmental, group or other horizontal boundary. In the advice network there were $14(15.2 \%), 12$ of which were directed from subordinate to superior. In the trust network there were only four.

Table 3. Distribution of Dyads in the Informal Structures of Leers Computer

\begin{tabular}{|c|c|c|}
\hline Dyads & Advice & Trust \\
\hline $\begin{array}{l}\text { Structural Equivalents—same hierarchical level (the } \\
\text { bottom) — and same superior }\end{array}$ & $18(19.6 \%)$ & $20(29.9 \%)$ \\
\hline $\begin{array}{l}\text { Regular Equivalents - same hierarchical level, same } \\
\text { superior, different subordinates }{ }^{3}\end{array}$ & $5(5.4 \%)$ & 0 \\
\hline $\begin{array}{l}\text { Regular Equivalents-same hierarchical level, different } \\
\text { superiors }\end{array}$ & $24(26.1 \%)$ & $34(50.7 \%)$ \\
\hline Non-equivalents—superior to subordinate & $3(3.3 \%)$ & \\
\hline Non-equivalents-subordinate to superior & $21(22.8 \%)$ & $6(9.0 \%)$ \\
\hline $\begin{array}{l}\text { Non-equivalents - upward and across both a hierarchical } \\
\text { and a departmental boundary }\end{array}$ & $12(13 \%)$ & $4(6.0 \%)$ \\
\hline $\begin{array}{l}\text { Non-equivalents - downward and across both a } \\
\text { hierarchical and a departmental boundary }\end{array}$ & $2(2.2 \%)$ & \\
\hline $\begin{array}{l}\text { Non-Equivalents-skip level upward in the scalar } \\
\text { chain/chain of command }\end{array}$ & $6(6.5 \%)$ & $3(4.4 \%)$ \\
\hline $\begin{array}{l}\text { Non-Equivalents-skip level downward in the scalar } \\
\text { chain/chain of command }\end{array}$ & $1(1.1 \%)$ & \\
\hline Total & 92 & 67 \\
\hline Number $(\%)$ of ties along the scalar chain & $31(33.7 \%)$ & $9(13.4 \%)$ \\
\hline Number (\%) of ties between equivalents & $47(51.1 \%)$ & $54(80.6 \%)$ \\
\hline $\begin{array}{l}\text { Number }(\%) \text { of ties crossing hierarchical and } \\
\text { departmental boundary }\end{array}$ & $14(15.2 \%)$ & $4(6.0 \%)$ \\
\hline
\end{tabular}

\section{Summary}

The above analysis of the informal networks at Leers Computer suggests that position in the formal structure strongly influences tie or dyad formation. Recall that in the advice network, some $51 \%$ of the ties are to others at the same level in the hierarchy. Of those at the same level, there was an approximately 3-to-2 split in favor of ties crossing a departmental boundary. Of those at different levels, there was a 6.5-to-1 ratio in favor of ties directed upward. In terms of the scalar chain, there was a 2:1 ratio in favor of ties directed off the chain of command, i.e. that crossed a departmental boundary. The trust network, by comparison, is much more lateral. Here almost $81 \%$ of the ties are between people at the same level of the hierarchy, with a 1.7-to-1 split in favor of ties to a different department. Thus, trust relations in this company were strongly predicated upon, if not predicted by, the hierarchical level of the parties.

Stepping back from numbers it's important to recognize one other similarity here. Advice seeking and trust are directed 
in such a way as to highlight the importance of the two aspects of differentiation in formal structure-vertical and horizontal, respectively. Recall that these two aspects of formal structure are typically measured by the number of levels in the hierarchy and the span-of-control or number of departments. As discussed earlier, these two are among the most graph-like measures of formal organization structure and they seem to have influenced tie or dyad formation. Specifically, those lower in the hierarchy sought out those higher than them for advice. But no matter what the level, trust ties were forged with those at the same level.

There also appears to have been an influence of the informal structure on the formal - but not one that manifests in or predicts tie formation. Rather, the key to understanding informal structure's impact upon formal structure concerns path distance. Recall that in both instances, the average geodesic distance of the informal network and of the combined network were smaller than that of the formal structure alone. When we look again at the typology with impact on path distance in mind, then it is immediately apparent that the eight types of dyads - or four if the ties in the informal network are undirected - do not have the same effect on path distance. In particular, informal ties between subordinates and superiors have no effect on the average geodesic distance because they are redundant, i.e. they link parties that are already connected in the formal structure. In marked contrast, ties that cross department or horizontal boundaries have a greater impact on average geodesic distance. And the impact is proportional to the path distance in the formal structure of the two parties. If both are at the bottom of the hierarchy, then the reduction in distance is the maximum. Given how much more lateral the trust network was compared to the advice network, it is expected that its average geodesic distance was so much smaller than that of the advice network- 1.862 vs. 2.571 , a difference of $28 \%$. Similarly, the combined network of trust and formal structure had an average geodesic distance that was $11 \%$ smaller than the combination of advice and formal structure. Thus, the greater the number or percentage of lateral ties, the greater the reduction in distance between nodes in the network. To our knowledge, no prior studies have noted this effect of informal structure on formal. Perhaps this is because, as noted earlier, the two are not discussed and described using similar terminology or analyzed as multiplex networks.

\section{Conclusion}

Recall that the primary purpose of this paper was demonstrate an approach by which informal and formal organization structure could be "treated empirically and conceptually together" (Tichy \& Fombrun, 1979) and thereby affect some kind of resolution of the persistent duality that they represent. Noting that each stream of research uses a very different conceptual vocabulary to define structure, the approach settled upon here was to identify a minimal set of terms that would allow formal and informal structure to be subjected to a "similar systematic analysis" (ibid). To that end we began with a discussion of whether and how Krackhardt's (1994) four graph theoretical dimensions (GTD) of informal structure could be applied to the definition and study of formal organization structure. It was established that those four dimensions are invariant across the common conceptualization of formal organization structure. However, it was also determined that variance in formal structure was found among widely studied, firm level measures like vertical span, i.e. the number of levels in the hierarchy, and span of control, i.e. the average number of subordinates per supervisor.

It was further shown that both of these measures are inherently graph theoretical and are highly correlated with well-established graph theoretical dimensions of structure, namely diameter and degree centrality, respectively. The application of these two measures, Krackhardt's four GTD, and a handful of other graph theoretical measures to a case study revealed further insights into the relationship between formal and informal structure. In particular, it was shown that position within formal structure seems to influence the formation of dyads and/or direction of ties in both networks. In the advice network, those higher in the network were disproportionately sought out for advice. This is consistent with prior research in advice-seeking in organizational settings, specifically law firms (Lazega \& Van Duijn, 1997; Creswick $\&$ Westbrook, 2010). In the trust network, dyads were formed disproportionately among employees at the same level. It was also shown that informal structural effects on formal structure. In particular, the case analysis showed that informal structure increases the reachability among nodes linked in the formal structure and it reduces the distance between them. In particular, it was demonstrated that every informal tie that is not aligned with the formal structure will reduce the distance between the pair of nodes. Notably, the two informal networks varied in the degree to which they reduced distance over the formal structure. Specifically, the advice network, which was more hierarchically aligned, produced a less dramatic reduction in geodesic distance than did the much more lateral trust network. Another insight of this study was the development of a typology that classifies dyads in an formal organization with only a small number of classical and graph theoretical dimensions of structure.

To the best of our knowledge, these effects of formal and informal structure on one another have not been previously acknowledged in the literature nor has any typology akin to the one developed herein been detailed. Further research will need to be undertaken to determine whether the effects observed in the case study are more generalizable. More theorizing may reveal a better classification scheme or typology than the one presented herein. 
Taken together, these findings have important implications for both literatures on the structure-performance relationship. Several studies in the last two decades have already linked graph theoretical measures of the informal structure to organization performance (Hunter, 2015). Future research might examine whether the degree to which an informal network foreshortens path distances in the formal structure is positively related to performance, especially performance at the departmental and business unit, and firm level. Another possibility is to examine whether and to what degree performance is affected by the distribution of ties in the informal network across categories of the presented typology. Of especial interest would be the three major groupings - ties along the scalar chain, ties between equivalents, and ties across levels and departments.

Research on formal structure and performance can also benefit from the application of insights demonstrated here. Very few empirical studies to date have reported direct effects of either vertical or horizontal aspects of structure on performance above the group/team level in organizational settings. Of those that have, not one makes mention of informal structure in any context, let alone considers the possibility that it effectively reduces distance across levels of the hierarchy and between subordinates of the same superior. Research on formal structure-performance relationship undertaken henceforth should examine whether and how this inter-relation with informal structure, and thereby help in resolving their duality.

\section{References}

Armandi, B. R., \& Mills, E. W. (1985). Bureaucratic and Personalized Strategies for Efficiency and Organization: An Investigation of Structures and Efficiency in a Set of 104 Profit - seeking Firms. American Journal of Economics and Sociology, 44(3), 261-277. http://dx.doi.org/10.1111/j.1536-7150.1985.tb02342.x

Blau, P. M. (1968). The hierarchy of authority in organizations. American Journal of Sociology, 73(4), 453-467.

Blau, P. M. (1970). A formal theory of differentiation in organizations. American Sociological Review, 35(2), 201-218.

Bolton, P., \& Dewatripont, M. (1994). The firm as a communication network. The Quarterly Journal of Economics, 109(4), 809-839.

Burton, R. M., \& Obel, B. (1998). Strategic Organizational Diagnosis and Design: Developing theory for Application. Springer Science \& Business Media.

Carillo, P. M., \& Kopelman, R. E. (1991). Organization Structure and Productivity Effects of Subunit Size, Vertical Complexity, and Administrative Intensity on Operating Efficiency. Group \& Organization Management, 16(1), 44-59. http:// 10.1177/105960119101600104

Creswick, N., \& Westbrook, J. I. (2010). Social network analysis of medication advice-seeking interactions among staff in an Australian hospital. International Journal of Medical Informatics, 79(6), 116-125. http://dx.doi.org/10.1016/j.ijmedinf.2008.08.005

Crowston, K., \& Howison, J. (2006). Hierarchy and centralization in free and open source software team communications. Knowledge, Technology \& Policy, 18(4), 65-85. http://10.1007/s12130-006-1004-8

Cummings, J. N., \& Cross, R. (2003). Structural properties of work groups and their consequences for performance. Social Networks, 25(3), 197-210. http://dx.doi.org/10.1016/S0378-8733(02)00049-7

Daft, R. (2012). Organization theory and design. Cengage learning.

Diefenbach, T., \& Sillince, J. A. (2011). Formal and informal hierarchy in different types of organization. Organization Studies, 32(11), 1515-1537. http://10.1177/0170840611421254

Donaldson, L. (1987). Strategy and structural adjustment to regain fit and performance: in defence of contingency theory. Journal of Management Studies, 24(1), 1-24. http:// 10.1111/j.1467-6486.1987.tb00444.x

Donaldson, L. (2001). The Contingency Theory of Organizations. Sage.

Doty, D. H., Glick, W. H., \& Huber, G. P. (1993). Fit, equifinality, and organizational effectiveness: A test of two configurational theories. Academy of Management Journal, 36(6), 1196-1250. http://10.2307/256810

Everett, M. G., \& Krackhardt, D. (2012). A second look at Krackhardt's graph theoretical dimensions of informal organizations. Social Networks, 34(2), 159-163. http://dx.doi.org/10.1016/j.socnet.2011.10.006

Gulati, R., \& Puranam, P. (2009). Renewal through reorganization: The value of inconsistencies between formal and informal organization. Organization Science, 20(2), 422-440. http://dx.doi.org/10.1287/orsc.1090.0421

Harris, T. E. (2002). Applied organizational communication: Principles and pragmatics for future practice. Routledge.

Hunter, S. (2015). Combining Theoretical Perspectives on the Organizational Structure-Performance Relationship. Journal of Organization Design, 4(2), 24-37. http://dx.doi.org/10.7146/jod.16781 
Kilduff, M., \& Krackhardt, D. (2008). Interpersonal Networks in Organizations: Cognition, personality, dynamics, and culture, Cambridge University Press.

Krackhardt, D. (1994). Graph theoretical dimensions of informal organizations. Computational Organization Theory, 89(112), 123-140.

Krackhardt, D., \& Hanson, J. R. (1993). Informal networks: The Company Behind the Chart. Harvard Business Review, 71(4), 104-111.

Lazega, E., \& Van Duijn, M. (1997). Position in formal structure, personal characteristics and choices of advisors in a law firm: A logistic regression model for dyadic network data. Social Networks, 19(4), 375-397. http://10.1016/S0378-8733(97)00006-3

Maguire, E. R. (2009). Police organizational structure and child sexual abuse case attrition. Policing: An International Journal of Police Strategies \& Management, 32(1), 157-179. http://dx.doi.org/10.1108/13639510910937175

Mehra, A., Dixon, A. L., Brass, D. J., \& Robertson, B. (2006). The social network ties of group leaders: Implications for group performance and leader reputation. Organization Science, 17(1), 64-79. http://dx.doi.org/10.1287/orsc.1050.0158

Meier, K. J., \& Bohte, J. (2000). Ode to Luther Gulick: Span of control and organizational performance. Administration \& Society, 32(2), 115-137. http://10.1177/00953990022019371

Miles, R. E., Snow, C. C., Meyer, A. D., \& Coleman, H. J. (1978). Organizational strategy, structure, and process. Academy of management review, 3(3), 546-562. http://10.5465/AMR.1978.4305755

Oberg, A., \& Walgenbach, P. (2008). Hierarchical structures of communication in a network organization. Scandinavian Journal of Management, 24(3), 183-198. http://dx.doi.org/10.1016/j.scaman.2008.03.011

Reagans, R., Zuckerman, E., \& McEvily, B. (2004). How to make the team: Social networks vs. demography as criteria for designing effective teams. Administrative Science Quarterly, 49(1), 101-133. http://10.2307/4131457

Reitzig, M., \& Maciejovsky, B. (2014). Corporate hierarchy and vertical information flow inside the firm a behavioral view. Strategic Management Journal, 36(13), 1979-1999. http://10.1002/smj.2334

Sarkar, A., Fienberg, S. E., \& Krackhardt, D. (2010). Predicting profitability using advice branch bank networks. Statistical Methodology, 7(3), 429-444. http://dx.doi.org/10.1016/j.stamet.2009.12.001

Sparrowe, R. T., Liden, R. C., Wayne, S. J., \& Kraimer, M. L. (2001). Social networks and the performance of individuals and groups. Academy of Management Journal, 44(2), 316-325. http://10.2307/3069458

Theobald, N. A., \& Nicholson-Crotty, S. (2005). The Many Faces of Span of Control: Organizational Structure across Multiple Goals. Administration \& Society, 36(6), 648-660. http://10.1177/0095399704270585

Tichy, N., \& Fombrun, C. (1979). Network analysis in organizational settings. Human Relations, 32(11), 923-965. http://10.1177/001872677903201103

\section{Notes}

Note 1: The pair are structurally equivalent if both are on the lowest level of the hierarchy and a regularly equivalent otherwise.

Note 2: The regular equivalents here and in the category just above are at the same hierarchical level but have different superiors. In the above case the regular equivalents are middle managers who report to the same supervisor, e.g. the head of advertising and the head of market research who both report to the Chief Marketing Officer (CMO). Here the regular equivalents are found on the same level and report to different supervisors who are at the same level, e.g. the $\mathrm{CMO}$ and the Chief Financial Officer, both of whom report to the CEO.

Note 3: Because this organization structure only had three levels in the hierarchy, this the middle tier, i.e. the Senior Vice Presidents (SVPs).

\section{$(\infty))$ EY}

This work is licensed under a Creative Commons Attribution 3.0 License. 